\title{
Tocopherol measurement in edible products of vegetable origin
}

\author{
Diego J.M. Gómez-Coronado ${ }^{\mathrm{a}}$, Elena Ibañez ${ }^{\mathrm{b}}$, F. Javier Rupérez ${ }^{\mathrm{a}}$, Coral Barbas ${ }^{\mathrm{a}, *}$ \\ ${ }^{a}$ Facultad C.C. Experimentales y de la Salud, Universidad San Pablo-CEU, 28668 Boadilla del Monte, Madrid, Spain \\ ${ }^{\mathrm{b}}$ Departamento de Caracterización de Alimentos, Instituto de Fermentaciones Industriales (CSIC), Juan de la Cierva 3, 28006 Madrid, Spain
}

Available online 15 September 2004

\begin{abstract}
Since natural antioxidants present increasing interest for food industry due to their beneficial effect on health, new potential sources have been screened among edible aromatic plants and a microalgae, Spirulina platensis. The determination was performed after optimising a previously validated method, because important differences have been found among values described in literature for tocopherol content in products of vegetable origin. Values obtained ranged from $3.42 \mathrm{mg} \alpha$-tocopherol $/ 100 \mathrm{~g}$ of dill to $132.2 \mathrm{mg} / 100 \mathrm{~g}$ of fresh bay and from $0.14 \mathrm{mg}$ $\gamma$-tocopherol/100 g of spearmint to $3.45 \mathrm{mg} / 100 \mathrm{~g}$ of parsley. In all cases results were calculated from fresh leaves. Preliminary experiments were developed with bay (Laurus nobilis) plant to devise the supercritical fluid extraction of tocopherols, generating environmentally friendly processes to selectively extract fractions enriched with antioxidant compounds while removing fractions corresponding to essential oils, that is, those that correspond to the characteristic aroma of the plants. Another striking result has been the tocopherol content in the microalgae, $1.3 \mathrm{mg} \alpha$-tocopherol/100 $\mathrm{g}$ of dried commercial spirulina, which do not justify the supposed source of antioxidant vitamins. Results suggest the need of more reliable determinations of tocopherols in vegetable sources to be included in databases.
\end{abstract}

(C) 2004 Elsevier B.V. All rights reserved.

Keywords: Vitamin E; Screening; Supercritical fluid extraction; Spirulina; Microalgae

\section{Introduction}

Tocopherols (vitamin E) are lipid-soluble antioxidants synthesized only by photosynthetic organisms $[1,2]$. These are present as constituents of unsaponifiable matter and may occur together with phospholipids, carotenoids, chlorophylls and triterpenyl alcohols.

The subject of natural antioxidants continues to captivate the interest of food and biomedical scientists, because of the reports that diets rich in plant antioxidants derived from fruits and vegetables are associated with lower risks of coronary heart disease and cancer [3,4].

Owing to the emerging evidence of the physiological importance concerning the balance of the different tocopherols in biological systems, the possible benefits of using natural tocopherol mixtures from plant origin as vitamin supplements in human nutrition should be considered when such medication seems necessary [5]. Furthermore, synthetic tocopherols

\footnotetext{
* Corresponding author. Fax: +34 913510475.

E-mail address: cbarbas@ceu.es (C. Barbas).
}

are not as biologically active as natural, due to non-active stereoisomers [6], not present in natural sources. Therefore, the importance of finding out vegetable compounds able to take effectively the role of conventional antioxidants, and their investigation and economical verification, is greatly increasing. Many medicinal and aromatic plants, spices and herbs have traditionally been used in foods to improve or modify their flavour. However, their protective effect for inhibiting oxidation plays an important role unknown for years and it could be related to their tocopherol content.

On the other hand, Spirulina platensis is a microalgae, which is said to be a recent re-discovery to the modern world as it shows several health effects [7]. As for its composition, S. platensis can be considered a natural source of therapeutical compounds since it has been described as containing significant amounts of $\beta$-carotene [8], inositol, niacin, $\alpha$-tocopherol and polyunsaturated fatty acids (PUFA) such as gamma-linolenic acid [9] and eicosapentaenoic acid [10], among others.

Data for the development of a database for tocopherol values for plants are derived from a wide variety of methods and 
studies, each of which has different drawbacks. Vitamin E is not chemically bound to proteins, lipids or carbohydrates [11] and using harsh reagents and conditions to free it up (e.g. strong saponification) can destroy the vitamins. However, if adequate conditions are not used to release the vitamin from lipophylic media, recoveries will be poor, because vitamin E could be associated to other matrix components and must freed up in the sample preparation steps. Many works, previously reviewed [12] provide data about hexanic, methanolic or other solvent extracts, but when samples have not been previously dried, the different water content in different samples makes the extraction ability of the same solvent different and therefore, the real content in the plant cannot be compared.

Even though vitamin $\mathrm{E}$ is synthesized by plants, analytical data of tocopherols content in vegetables found in bibliography are quite different and sometimes are undervalued comparing to traditional vitamin $\mathrm{E}$ rich oils (wheat germ oil). Found $\alpha$-tocopherol contents of 16 Mediterranean Basin plant leaves varied from 1.8 to $84.6 \mathrm{mg} / 100 \mathrm{~g}$ of dried leaves $[13,14]$ and those of six edible plants did from $28 \mathrm{mg}$ to $619 \mathrm{mg} / 100 \mathrm{~g}$ of dried weight were in some cases greater than those of soybeen, rapeseed, sunflower and corn oils [15].

Our research group developed and validated an HPLC method for measuring $\alpha$-tocopherol content in Rosemarinus officinalis and we could observe important differences with other values described in literature [16]. Afterwards, we optimised and validated the method for Laurus nobilis [17].

The aim of the present work was the optimisation of the previously developed method to be applied to different plants to measure their tocopherol content. Our main goal was to identify new potential natural sources of antioxidants, thus, a preliminary screening was performed considering different edible aromatic plants and a microalgae. Moreover, preliminary assays were developed to evaluate the supercritical fluid extraction (SFE) of tocopherols in the plant with higher tocopherol content. Also, in the present study we attempt to show that tocopherol values in different databases ought to be revised in many cases.

\section{Experimental}

\subsection{Reagents and standards}

All solvents were HPLC grade quality purchased from Scharlab (Barcelona, Spain). $\alpha$-Tocopherol, lycopene, $\beta$ carotene, chlorophyll $a$ and $b$ were from Fluka (Buchs SG, Switzerland) and $\gamma$-tocopherol and lutein were from Sigma (St. Louis, MO, U.S.A.). Tocol was a kind gift from Roche (Basel, Switzerland).

\subsection{Plant material}

Bay (L. nobilis), rosemary (R. officinalis), sage (Salvia sp.), thyme (Thymus sp.) and marjoram (Mejorana hortensis) wild plants were from different locations of Madrid Community. Dill (Anethum graveolens), basil (Ocimun basilicum), coriander (Coriandrum sativum), spearmint (Mentha spicata), peppermint (Mentha piperita), oregano (Origanum vulgare), parsley (Petroselinum crispum) plants were grown in a greenhouse (Herbex, El Ejido, Almería, Spain) and were purchased in a local market. Dried S. platensis was bought to a local supplier (Algamar, Spain).

\subsection{Optimisation of sample treatment}

\subsubsection{Drying procedure}

Microwave drying has been used in the present study, as previously suggested [18]. In order to establish the need of optimisation of the drying time for the different plants, considering their different water content, two pools of leaves of six different plants were dried using both, the minimum and the maximum drying time (just before they got burnt). In all of them, $\alpha$-tocopherol content was determined as described below.

\subsubsection{Extraction}

Four different solvents were tested for their extraction efficiency: acetone, tetrahydrofuran, isopropanol and hexane. In all cases, $\alpha$ - and $\gamma$-tocopherol content in three ground rosemary and oregano dry leaves samples were measured. These plants were chosen to cover a wide range of water and $\alpha$ - and $\gamma$-tocopherol contents.

Samples were prepared by adding $3.8 \mathrm{ml}$ of the corresponding solvent to $250 \mathrm{mg}$ of bay leaves, $200 \mu \mathrm{l}$ of tocol of the dissolution with the internal standard (see below). Samples were processed simultaneously and in parallel with the corresponding standards diluted in acetone. In the case of the samples extracted with hexane, to avoid the incompatibility with the mobile phase, $2 \mathrm{ml}$ of the extract were evaporated under nitrogen and redissolved in $2 \mathrm{ml}$ of mobile phase.

\subsubsection{Conservation}

An homogeneous pool of dry ground rosemary leaves was prepared and kept in closed plastic containers half in a refrigerator and the other half in a dessicator and darkness. The $\alpha$-tocopherol content was determined on the same day that the pool was prepared and one week, two weeks, one and three months later using standards freshly prepared on the day of the analysis.

\subsection{Final quantification procedure}

\subsubsection{Stock and working standards}

Individual stock solutions of about $9 \mathrm{mg} / \mathrm{ml}$ of $\alpha$ - and $\gamma$-tocopherol as external standards and a stock solution of $2 \mathrm{mg} / \mathrm{ml}$ tocol as internal standard were prepared in ethanol. These solutions were stored in aluminium foil-covered containers and kept at $-20^{\circ} \mathrm{C}$. The day of the assay, the exact concentration of $\alpha$ - and $\gamma$-tocopherol was determined spectrophotometrically in an ethanol dilution 1/250 (v/v). Lec- 
tures were at $295 \mathrm{~nm}$ for $\alpha$-tocopherol $(\varepsilon=30581 / \mathrm{mol} \mathrm{cm})$ and at $298 \mathrm{~nm}$ for $\gamma$-tocopherol $(\varepsilon=3810 \mathrm{l} / \mathrm{mol} \mathrm{cm})$. Meanwhile dilutions in acetone $1 / 6(\mathrm{v} / \mathrm{v})$ of $\alpha$-tocopherol, $1 / 800$ of $\gamma$-tocopherol and 1/15 of tocol from the corresponding stocks were prepared. Finally working standards consisted of a mixture of $200 \mu \mathrm{l}$ of diluted tocol and $300 \mu \mathrm{l}$ of each diluted tocopherol made up with acetone to a final volume of $4 \mathrm{ml}$ in glass tubes. These solutions were probe sonicated and centrifuged to follow the same procedure as with samples.

\subsubsection{Sample treatment}

Approximately $5 \mathrm{~g}$ of fresh leaves were weighed before and after drying in a microwave oven at $900 \mathrm{~W}$ for $1 \mathrm{~min}$ to calculate their water content. After grinding $(20,000 \mathrm{rpm}$ for $15 \mathrm{~s}$ ), a mean particle size of less than $0.4 \mu \mathrm{m}$ was reached. Two hundred and fifty milligrams of the powder were weighed in a glass tube and $200 \mu l$ of diluted tocol and $3.8 \mathrm{ml}$ of acetone were added. Samples were extracted by probe sonication for $1 \mathrm{~min}$, centrifuged and filtered through $0.45 \mu \mathrm{m}$ nylon filters to HPLC vials.

\subsubsection{Chromatographic conditions}

The chromatographic system was a Beckman (Fullerton, CA, U.S.A.) HPLC system equipped with a 125 pump, an automatic injector (507e), a 168 diode array detector, a Gold System data processor, and an analogue interface (406) for the 470 fluorescence detector from Waters (Milford, MA, U.S.A.). Chromatographic analysis was performed on a $5 \mu \mathrm{m}$ particle Discovery ${ }^{\circledR} \mathrm{C} 18$ (Supelco, Bellefonte, PA, U.S.A.) column $(25 \mathrm{~cm} \times 0.46 \mathrm{~cm})$ kept in a Bio-Rad (Hercules, CA, U.S.A.) column oven at $35^{\circ} \mathrm{C}$. A $\mathrm{C}_{18}$ pre-column was used to protect the column from less polar compounds.

Purified-for-HPLC water (Milli-Q system, Millipore, Billerica, MA, U.S.A.) was employed as mobile phase A and acetonitrile-methanol $(70: 30, \mathrm{v} / \mathrm{v})$ with $0.1 \%(\mathrm{v} / \mathrm{v})$ of acetic acid added as mobile phase B. From $t=0$ to $t=24 \mathrm{~min}$ the eluent composition varied in a linear gradient from 85 to $100 \% \mathrm{~B}$ at a flow rate of $2 \mathrm{ml} / \mathrm{min}$. At $t=24 \mathrm{~min}$ the flow was increased to $3 \mathrm{ml} / \mathrm{min}$ in $1 \mathrm{~min}$ to clean the column of less polar compounds. At $t=35 \mathrm{~min}$ the system returned to initial conditions in $1 \mathrm{~min}$ which marked the end of the run. $\alpha$-Tocopherol was detected by absorbance at $295 \mathrm{~nm}$ and of both tocopherols by fluorescence exc: $295 \mathrm{~nm}$ em: $350 \mathrm{~nm}$.

Peak identification was performed comparing the retention times with pure standards, and confirmed with characteristic spectra obtained from the photodiode array detector, which also permitted the confirmation of the purity of the peaks.

Representative chromatograms of a rosemary sample are included in Fig. 1.

\subsection{Determination of $\alpha$ - and $\gamma$-tocopherol in edible aromatic plant leaves}

The analytical method was applied to the determination of $\alpha$ - and $\gamma$-tocopherol content in a unique sample of 12

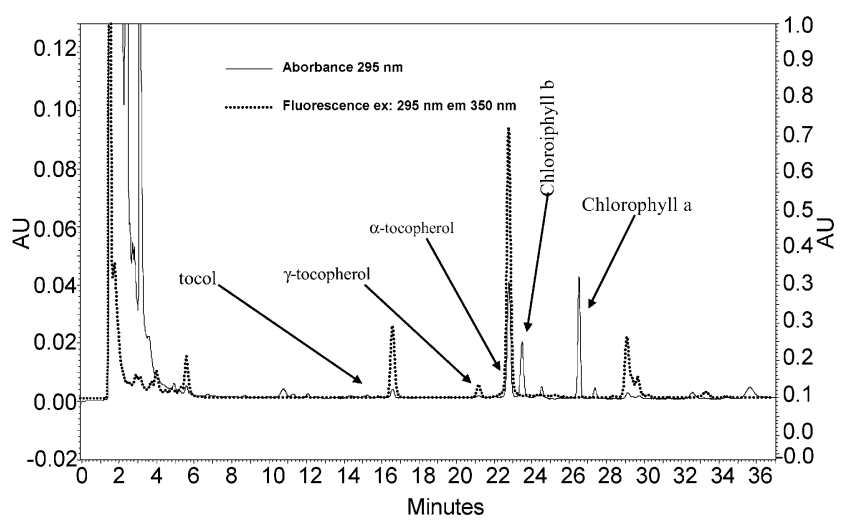

Fig. 1. Chromatograms with UV absorbance detection at $295 \mathrm{~nm}$ and fluorescence detection at excitation of $295 \mathrm{~nm}$ and emission of $350 \mathrm{~nm}$ of rosemary leaf samples with the following final chromatographic conditions: $\mathrm{C} 18$ Discovery $(25 \mathrm{~cm} \times 0.46 \mathrm{~cm})$ column at $35^{\circ} \mathrm{C}$ and mobile phases A [purifiedfor-HPLC water] and B [acetonitrile/methanol (70:30, v/v) with $0.1 \%(\mathrm{v} / \mathrm{v})$ of acetic acid added] using the gradient described in the text.

fresh aromatic plant leaves: basil, coriander, dill, peppermint, spearmint, bay, marjoram, oregano, parsley, rosemary, sage and thymus plus the commercial microalgae Spirulina.

\subsection{Seasonal variability in the $\alpha$ - and $\gamma$-tocopherol content in rosemary leaves}

The $\alpha$ - and $\gamma$-tocopherol content in rosemary leaves from the same plant, grown in open air, were determined every month from November to August.

\subsection{Supercritical fluid extraction experiment}

\subsubsection{Sample treatment}

Five grams portions of bay leaves were dried in microwave oven during $1 \mathrm{~min}$ at $900 \mathrm{~W}$. Samples were weighed before and after drying procedure to calculate their humidity. Afterwards, they were grounded and sieved throughout 0.2 and $0.6 \mathrm{~mm}$ sieves. The fraction from 0.2 to $0.6 \mathrm{~mm}$ mean particle size was used to perform the SFE experiments.

\subsection{2. $S F E$}

A Suprex PrepMaster (Suprex Corporation, Pittsburgh, PA, U.S.A.) supercritical fluid extractor was used to carry out all the experiments. Approximately $1.7 \mathrm{~g}$ of ground dried bay leaves were introduced into a $5 \mathrm{ml}$ stainless steel extraction cell. Supercritical $\mathrm{CO}_{2}$ flow rate was controlled using a needle valve as variable restrictor; flow rates between 3 and $4 \mathrm{ml} / \mathrm{min}$ were obtained at the experimental conditions tested. Samples were extracted at $40^{\circ} \mathrm{C}$, but using four different extraction pressures to cover a wide range of densities: $100 \mathrm{bar}$ $(0.622 \mathrm{~g} / \mathrm{ml}) ; 200 \mathrm{bar}(0.840 \mathrm{~g} / \mathrm{ml}) ; 300 \mathrm{bar}(0.910 \mathrm{~g} / \mathrm{ml})$ and $400 \mathrm{bar}(0.956 \mathrm{~g} / \mathrm{ml})$. Extraction time was $5 \mathrm{~min}$ static followed by $60 \mathrm{~min}$ in dynamic mode. Supercritical fluid extracts were collected in a special device [29] previously designed to minimize losses of material. The device is composed by 
a two-pieces chamber; the lower part contains a replaceable glass test vial $(2 \mathrm{~cm} \times 0.5 \mathrm{~cm})$ previously weighed where the extract is deposited during the extraction. The vial is surrounded by a cooling jacket that can be refrigerated at a target temperature by using a convenient gas or liquid. Consecutive extractions with new plant material were conducted to obtain enough amount of each extract: three for $100 \mathrm{bar}(16.3 \mathrm{mg}$ extract) and 200 bar (51.6 mg extract), two for $300 \mathrm{bar}(41.1 \mathrm{mg}$ extract) and just one for 400 bar (24.7 mg extract).

\subsubsection{Determination of extraction percentage}

The fraction of mean particle size between 0.6 and $0.2 \mathrm{~mm}$ was analysed by HPLC with the method described above, previous to SFE extraction to determine $\alpha$ - and $\gamma$-tocopherol initial bay contents (it was considered $100 \%$ in Table 2). Then, residual ground bay leaves obtained after each extraction were analysed too to obtain the remaining $\alpha$ - and $\gamma$-tocopherol bay contents. Finally the percentage extracted was calculated by difference and taking into account the exact weight of ground bay used in each extraction.

\section{Results and discussion}

Treatment for $1 \mathrm{~min}$ in microwave oven $(900 \mathrm{~W})$ has demonstrated its efficacy as drying procedure with rosemary [16] and bay leaves [17] in previous works of our group. These two leaves have similar water content (50 and 60\%, respectively), but it was not so for the rest of leaves studied in the present work, which water contents ranged from 50 to $90 \%$. Leaves with higher water content, such as basil, parsley, sage, dill and coriander got dried in $45 \mathrm{~s}$ but could tolerate $1 \mathrm{~min}$ before they got burned. On the other hand, leaves with lower water content such as rosemary could tolerate $1 \mathrm{~min}$ and $15 \mathrm{~s}$. In order to determine if it was necessary to optimise a drying time in microwave oven for each plant or a common time could be employed, two groups were analysed with maximum and minimum treatment time. No statistical difference in $\alpha$-tocopherol content was found with one tail Student paired $t$-test $(P>95 \%)$ neither between drying time or water content in each pool, nor between both pools and therefore, $1 \mathrm{~min}$ was established for drying all type of samples.

Samples must be submitted to stages of extraction and/or cleaning previous to their injection in the chromatographic system. Saponification was rejected because it is time consuming, its severe conditions can degrade tocopherols, and it has been previously demonstrated that it is not necessary if adequate extraction and chromatographic conditions are employed $[16,19,20]$. For extraction, three different solvents were tested along with acetone, which had previously shown its adequacy with rosemary [16], and bay leaves [17]. In all cases the extraction protocol described in materials and methods section was followed. The amount of solvent was previously optimised considering the highest solvent to sample ratio that gave signals over the limit of quantification for

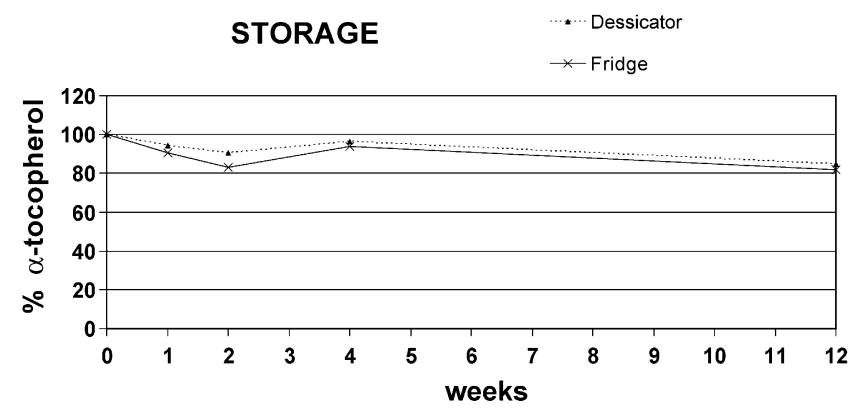

Fig. 2. $\alpha$-Tocopherol content variation in dessicated and ground rosemary leaves stored in fridge or dessicator and darkness.

the whole range. That guarantees the highest extraction efficiency. Regarding the sonication it was performed at $20 \mathrm{kHz}$ for $1 \mathrm{~min}$. Lower extraction time does not improve the method significantly, while higher sonication time can increase free radical generation and provide tocopherol consumption. After one-way ANOVA, means of the measured concentrations were compared with the Student-Newman-Keuls multiple range test, and there were no significant differences among the different solvents for both analytes and all of them belonged to the same homogeneous group. But, because results obtained with acetone were slightly higher than with the other three, its behaviour is well know and is less expensive than the others, acetone was finally chosen as the extraction solvent for the rest of the experiments. A second extraction was performed with samples extracted with acetone and the tocopherol recovery was negligible in all cases.

Tocopherols are easily oxidized and oxidation losses can be incremented by heat, light, alkaline $\mathrm{pH}$ and by the presence of free radicals. This is especially critical in samples in which vitamin $E$ can be oxidized during the extraction process and/or in the extract until its final analysis. Nevertheless, the addition of antioxidants is not considered necessary, except in the case of simultaneous analysis of more labile compounds, special matrices or when saponification is applied [12]. Due to the characteristics of tocopherols and because sometimes samples cannot be analysed on the same day that they were collected, a stability assay was performed to determine the best way of sample storing and the stability of dessicated samples. In Fig. 2, the percentage of $\alpha$-tocopherol related to the initial content is represented versus the storage time for samples kept in both, the refrigerator and the dessicators at darkness. Recoveries were very similar in both cases but were slightly higher in dessicator and darkness. Therefore, collected samples were kept dried and ground in the dessicator and in darkness until their use.

Aromatic plants have been traditionally used as food condiments, probably due not only to their aroma, but also to their antioxidant properties to prevent rancidity caused by the oxidation of fatty foods. One of these oxidation processes is lipid peroxidation chain reaction that specially affects to those foods with higher polyunsaturated fatty acids, like seeds oils. These oils are naturally rich in tocopherols but refine- 
Table 1

$\alpha$-Tocopherol $(\alpha-\mathrm{T})$ and $\gamma$-tocopherol $(\gamma$-T) contents $(\mathrm{mg} / 100 \mathrm{~g}$ fresh leaves) obtained by fluorescence with validated analytical method; content found in the USDA Nutrient Database for Standard Reference (SR) release 14 [30] and in other references found in bibliography

\begin{tabular}{|c|c|c|c|c|c|}
\hline & \multicolumn{2}{|l|}{ Validated method } & \multirow{2}{*}{\multicolumn{2}{|c|}{$\begin{array}{l}\text { USDA (mg } \alpha-T E / 100 g \\
\text { edible fraction) }\end{array}$}} & \multirow[t]{2}{*}{ Other methods $(\alpha-T)$} \\
\hline & $\alpha-\mathrm{T} \mathrm{mg} / 100 \mathrm{~g}$ fresh & $\gamma$-T mg/100g fresh & & & \\
\hline Basil & 4.05 & 0.69 & 1.69 & Basil, ground & \\
\hline Coriander & 7.60 & 0.20 & 1.03 & Coriander leaf, dried & \\
\hline Dill & 3.42 & 0.50 & & & \\
\hline Spearmint & 6.04 & 0.14 & 0.34 & Spearmint, fresh & \\
\hline Bay & 132.2 & 1.15 & 1.79 & Bay leaf, crumbled & $12.6 \mathrm{mg} / 100 \mathrm{~g}$ fresh $[31]$ \\
\hline Marjoram & 32.34 & 0.42 & 1.69 & Marjoram, dried & \\
\hline Peppermint & 4.92 & 0.15 & 0.34 & Peppermint, fresh & \\
\hline Oregano & 7.94 & 0.37 & 1.69 & Oregano, ground & $5.5 \mathrm{mg} / 100 \mathrm{~g}$ dried [32]; $21.3 \mathrm{mg} / 100 \mathrm{~g}$ fresh [31] \\
\hline Parsley & 5.14 & 3.27 & 1.79 & Parsley, raw & $29 \mathrm{mg} / 100 \mathrm{~g}$ fresh $[33]$ \\
\hline Rosemary & 31.62 & 0.36 & 0.78 & Rosemary, fresh & $3.5 \mathrm{mg} / 100 \mathrm{~g}$ dried [34], $100 \mathrm{mg} / 100 \mathrm{~g}$ dried [16]. \\
\hline Sage & 26.48 & 0.42 & 1.69 & Sage, ground & $49 \mathrm{mg} / 100 \mathrm{~g}$ fresh $[33]$ \\
\hline Thyme & 20.61 & 0.38 & 1.69 & Thyme, ground & \\
\hline Spirulina & $1.3^{\mathrm{a}}$ & N.D. & & & \\
\hline
\end{tabular}

${ }^{\mathrm{a}} \mathrm{mg} / 100 \mathrm{~g}$ of dried commercial spirulina.

ment processes deplete their contents, so, addition of "extra" antioxidant is necessary. The searching of alternatives to the use of synthetic and, at some extent, toxic antioxidant compounds like BHT or BHA has made possible the evaluation of hundreds of raw materials containing substances with antioxidant activity like herbs and spices and their extracts. Some of them have been traditionally used, not only for their flavour characteristics, but also as food preservatives [21-23]. Most of the studies had focused in plants of the Labiatae family, such as sage and rosemary. For example, extracts of these plants have been evaluated as antioxidants in rapeseed oil [24]. Addition of rosemary leaves to stored dressing exposed to light or in darkness resulted in a significantly better antioxidative protection than propylgallate addition [23]. Therefore, the use of spices and herbs as antioxidants in processed foods is a promising alternative to the use of synthetic antioxidants.

Most studies have so far concentrated on the antioxidant effects of rosemary and rosemary extracts. However, the strong and characteristic flavour of rosemary might limit the use of this spice despite the well-established and very high antioxidant capacity. Compared to other spices belonging to the Labiatae family, rosemary has the more intense flavour, which could be recognized at a lower level in meat balls compared to the flavours of the spices summer savory, Chilean oregano and sage. This observation increased the interest in other spices, since they remain sensory-acceptable when added in a larger amount than rosemary. A number of foods, such vegetable oils and dressings, are exposed to light during retail display or in the kitchen of consumers. Light is harmful to many foods as it initiates oxidation and, as the levels of free radicals increases through photo-oxidation, the induction period for oxidation may decrease due to the depletion of radical-scavenging. As mentioned before, antioxidant activity of some of the plant leaves can be associated to the presence of tocopherols, thus, quantification of both, $\alpha$ - and $\gamma$-tocopherol was carried out.
Previously, the analytical method was optimised and validated considering the whole process, that is, the sample treatment and the chromatographic conditions. The validation was performed by using bay leaves as test sample. Tocopherols were measured considering different detection modes, that is, $\alpha$-tocopherol by using a diode array detector at $295 \mathrm{~nm}$ and $\gamma$ tocopherol a fluorescence detector at excitation wavelength of $295 \mathrm{~nm}$ and emission wavelength of $350 \mathrm{~nm}$. The optimised method was lately used to measure tocopherol content in different aromatic plants. Table 1 shows $\alpha$ - and $\gamma$-tocopherol content of the different aromatic plants considered in the present study, and obtained by using the analytical method developed in our laboratory, along with data from different sources such as the USDA Nutrient Database.

From our results it can be seen that bay has the highest level of $\alpha$-tocopherol while parsley leaves show the highest content of $\gamma$-tocopherol. The volatile oil component, notably myristicin and apiol, is said to be responsible for the diuretic action of parsley in natural medicine, but recently it has been probed that a degradation product of $\gamma$-tocopherol, $\gamma$-CEHC, presents that action too $[25,26]$.

Important variations can be observed for the different plants with values for $\alpha$-tocopherol ranging from $132 \mathrm{mg}$ (bay leaves) to $3.4 \mathrm{mg}$ (dill), this differences can be somehow linked to a different leaf texture but it must be noticed that results are expressed per $100 \mathrm{~g}$ of fresh leaves; if they were expressed per $100 \mathrm{~g}$ dried leaves differences would not be so high. It is interesting to observe the high $\alpha$-tocopherol content of plants with proved antioxidant activity, such as rosemary or sage, indicating the possible relationship between tocopherol content and functional activity. More studies are conducted at present in our laboratory to verify this statement. Comparing our results with those of the USDA, when available, it seems that the USDA method underestimates the tocopherol content in that type of samples.

In the case of spirulina, as it came dried, four different samples were analysed. One of them directly, and three 
Table 2

$\alpha$-Tocopherol $(\alpha-\mathrm{T})$ and $\gamma$-tocopherol $(\gamma-\mathrm{T})$ contents obtained before and after SFE experiments and $\%$ extracted in each condition

\begin{tabular}{|c|c|c|c|c|c|c|}
\hline \multicolumn{2}{|c|}{ Initial tocopherol bay contents } & \multirow{2}{*}{$\begin{array}{l}\text { Supercritical fluid } \\
\text { extraction conditions }\end{array}$} & \multicolumn{2}{|c|}{ Residual tocopherol bay contents } & \multicolumn{2}{|c|}{$\%$ Extracted } \\
\hline $\begin{array}{l}\alpha-\mathrm{T} \\
(\mathrm{mg} / 100 \mathrm{~g} \text { dried })\end{array}$ & $\begin{array}{l}\gamma-\mathrm{T} \\
(\mathrm{mg} / 100 \mathrm{~g} \text { dried })\end{array}$ & & $\begin{array}{l}\alpha-\mathrm{T} \\
(\mathrm{mg} / 100 \mathrm{~g} \text { dried })\end{array}$ & $\begin{array}{l}\gamma-\mathrm{T} \\
(\mathrm{mg} / 100 \mathrm{~g} \text { dried })\end{array}$ & $\alpha-\mathrm{T}$ & $\gamma-\mathrm{T}$ \\
\hline \multirow{4}{*}{207.8} & \multirow{4}{*}{2.0} & $40^{\circ} \mathrm{C} ; 100 \mathrm{~atm}$ & 73.48 & 1.67 & 64.65 & 16.36 \\
\hline & & $40^{\circ} \mathrm{C} ; 200 \mathrm{~atm}$ & 50.44 & 1.11 & 75.73 & 44.41 \\
\hline & & $40^{\circ} \mathrm{C} ; 300 \mathrm{~atm}$ & 44.81 & 0.86 & 78.44 & 56.93 \\
\hline & & $40^{\circ} \mathrm{C} ; 400 \mathrm{~atm}$ & 45.41 & 0.80 & 78.15 & 59.93 \\
\hline
\end{tabular}

SEASONAL VARIABILITY OF TOCOPHEROL IN ROSEMARY

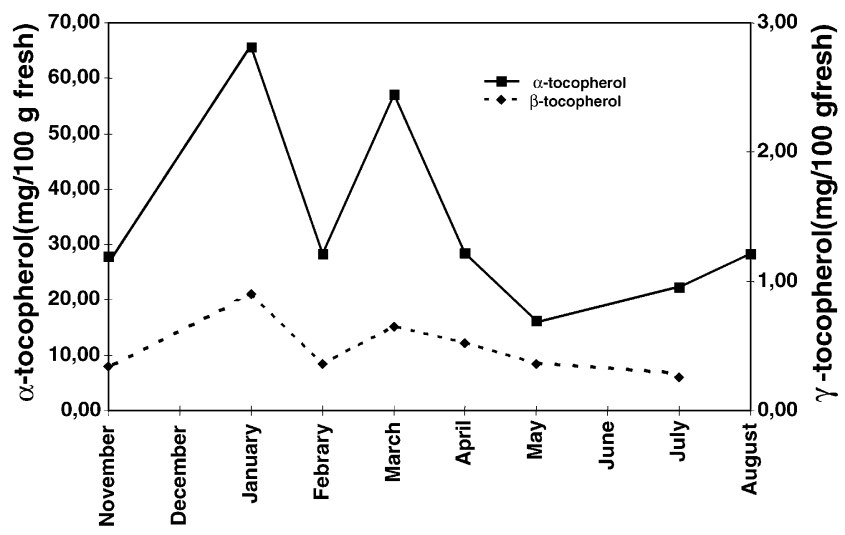

Fig. 3. Seasonal variability of $\alpha$ - and $\gamma$-tocopherol contents of rosemary leaves.

of them after a $60 \%(\mathrm{w} / \mathrm{w})$ water addition and 1, 2 and 3 min of microwave treatment to evaluate the possible effect of microwaves. Results were in all cases very similar, ranging from 0.011 to $0.014 \mathrm{mg} \alpha$-tocopherol/g dried spirulina. Data in literature about tocopherol content in Spirulina are relatively old and scarce, and reported values [27] are considerably higher $(0.12 \mathrm{mg} / \mathrm{g}$ dry weight $)$ than ours. Differences may be related with two different aspects: the samples measured in our laboratory were not cultured and dessicated by us, but acquired in the commercial form, industrially dessicated. Moreover, it must be taken into account that the results from Vincenzini et al. were obtained with a method that combined colorimetric determination after reaction with the Emmerie-Engel reagent with the compounds separated by TLC. Overestimation of real content of tocopherols may have occurred due to artefacts of the laborious sample processing. Regarding $\gamma$-tocopherol, results indicated that the content was under $0.05 \mathrm{mg} / 100 \mathrm{~g}$, which was the limit of detection of the method.

In order to check the ability of the analytical method to detect variations in $\alpha$ - and $\gamma$-tocopherol content in plants throughout the year, the variation in tocopherols in one rosemary plant grown at the University gardens in open air and at atmospheric conditions was evaluated from November to August. Results are expressed in Fig. 3. In general terms, both tocopherol contents were higher in winter than in summer; this results are in agreement with previous works that showed an increase in antioxidant protection for plants grown at low temperatures [28].

As previously mentioned (Table 1), bay was the plant with the highest $\alpha$-tocopherol content among the plant tested, and its $\gamma$-tocopherol was also significant. For this reason it seemed interesting to evaluate the possibility of using a different extraction method, such supercritical fluid extraction, to obtain extracts enriched in tocopherols. These experiments involved the extraction of dry bay leaves at four different conditions obtained by considering extraction pressures ranging from 100 to 400 bar. Results obtained are shown in Table 2. At conditions of higher density (higher pressure), higher percentages were obtained for both tocopherols although their extracts probably were less concentrated in both analytes because at higher pressures more lipids are expected to be extracted and therefore, yields were also higher and a lower number of extraction experiments were required to obtain enough amount of extract. The use of SFE can be interesting from different points of view; in a first place, SFE shows several advantages over conventional extraction techniques such as the use of non-toxic solvents and a higher extraction efficiency (due to the special characteristics of the supercritical fluids in terms of diffusion and solvent strength); also, considering the importance of antioxidant addition as a preservation method for the food industry, the possibility of developing environmentally friendly processes such as SFE to obtain extracts concentrated in compounds of specific functional properties can be of great importance. Moreover, SFE has demonstrate its ability to selectively extract fractions enriched with antioxidant compounds while removing fractions corresponding to essential oils, that is, those that correspond to the characteristic aroma of the plants [29].

\section{Acknowledgements}

MCYT project AGL2002-04621-C02-01 and San PabloCEU University project 16/03 for economical support.

\section{References}

[1] G. Schultz, A. Heintze, P. Hoppe, P. Hagelstein, J. Gorlach, K. Meereis, U. Schwanke, M. Preiss, in: E.J. Pell, K.L. Steffen (Eds.), Proceedings of the 6th Annual Penn State Symposium in Plant Physiology: Active Oxygen/Oxidative Stress and Plant Metabolism, Uni- 
versity Park, Pennsylvania, American Society of Plant Physiologists, Rockville, MD, 1991, p. 156.

[2] A.N. Yerin, Y. Kormanovskii, I.I. Ivanov, Biophysics 29 (1984) 363.

[3] A. Harris, S. Devaraj, I. Jialal, Curr. Atheroscler. Rep. 4 (2002) 373.

[4] R. Brigelius-Flohe, F.J. Kelly, J.T. Salonen, J. Neuzil, J.M. Zingg, A. Azzi, Am. J. Clin. Nutr. 76 (2002) 703.

[5] H.-U. Melchert, E. Pabel, J. Am. Oil Chem. Soc. 75 (1998) 213.

[6] R. Brigelius-Flohe, M.G. Traber, FASEB J. 13 (1999) 1145.

[7] DIC's Spirulina: Therapeutic Effects [Web Page]. Available at http://www.dic.co.jp/eng/products/lina/lina14.html.

[8] R. Kapoor, U. Mehta, Plant Foods Hum. Nutr. 43 (1993) 1.

[9] G. Mahajan, M. Kamat, Appl. Microbiol. Biotechnol. 43 (1995) 466.

[10] D.S.H.Y.M. Cohen Z, Plant Physiol. 98 (1992) 569.

[11] E. Herrera, Nutr. Obes. 3 (2000) 4.

[12] F.J. Ruperez, D. Martin, E. Herrera, C. Barbas, J. Chromatogr. A 935 (2001) 45.

[13] S. Chevolleau, J.F. Mallet, A. Debal, E. Ucciani, J. Am. Oil Chem. Soc. 70 (1993) 807.

[14] C. Cerrati, J.F. Mallet, E. Ucciani, J. Gamisans, M. Gruber, Riv. Ital. Sostanze Grasse 69 (1992) 317.

[15] R. Sridhar, G. Lakshminarayana, J. Agric. Food Chem. 41 (1993) 61.

[16] J. Torre, M.P. Lorenzo, M.P. Martinez-Alcazar, C. Barbas, J. Chromatogr. A 919 (2001) 305.

[17] D.J.M. Gómez-Coronado, C. Barbas, J. Agric. Food Chem. 51 (2003) 5196.

[18] S. Hippeli, K. Dornisch, M. Brink, R. Lorenz, D. Jeschke, E.F. Elstner, Z. Naturforch. 58 (2003) 119.

[19] F.J. Ruperez, C. Barbas, M. Castro, S. Martinez, E. Herrera, J. Chromatogr. A 823 (1998) 483.
[20] F.J. Ruperez, C. Barbas, M. Castro, E. Herrera, J. Chromatogr. A 839 (1999) 93

[21] N. Nakatani, ACS Symp. Ser. 507 (1992) 72.

[22] D. Bauman, M. Hadolin, A. Rizner-Hras, Z. Knez, Acta Alimentaria 28 (1999) 15.

[23] H.L. Madsen, B. Sorensen, L.H. Skibsted, G. Bertelsen, Food Chem. 63 (1998) 173.

[24] L. Trojakova, Z. Reblova, H.T.T. Nguyen, J. Pokorny, J. Food Lipids 8 (2001) 1.

[25] E.D. Murray, W.J. Wechter, D. Kantoci, W.H. Wang, T. Pham, D.D. Quiggle, K.M. Gibson, D. Leipold, B.M. Anner, J. Pharmacol. Exp. Ther. 282 (1997) 657.

[26] W.J. Wechter, D. Kantoci, E.D.J. Murray, D.C. D’Amico, M.E. Jung, W.H. Wang, Proc. Natl. Acad. Sci. U.S.A. 93 (1996) 6002.

[27] M. Vincenzini, F. Ferrari, M.O. Margheri, G. Florenzano, Microbiologica 3 (1979) 131.

[28] J. Leipner, Y. Fracheboud, S. Peter, Env. Exp. Bot. 42 (1999) 129.

[29] E. Ibáñez, A. Oca, G.d. Murga, S. López-Sebastian, J. Tabera, G. Reglero, J. Agric. Food Chem. 47 (1999) 140.

[30] A. R.S. 2. U.S. Department of Agriculture, USDA Nutrient Database for Standard Reference, Release 14 [Web Page]. Available at Nutrient Data Laboratory Home Page, http://www.nal.usda. gov/fnic/foodcomp, Accessed 25 July 2002.

[31] L.M. Marero, S. Homma, K. Aida, M. Fujimaki, J. Nutr. Sci. Vitaminol. 32 (1986) 131.

[32] V. Lagouri, D. Boskou, Int. J. Food Sci. Nutr. 47 (1996) 493.

[33] S. Philosoph-Hadas, S. Meir, B. Akiri, J. Kanner, J. Agric. Food Chem. 42 (1994) 2376.

[34] S. Munné-Bosch, K. Schwarz, L. Alegre, Z. Naturforch. 54 (1999) 698. 